\title{
Complementary and alternative medicine use by patients with inflammatory bowel disease: Are Canadian physicians failing with conventional therapy, or not?
}

\author{
Charles N Bernstein MD
}

\begin{abstract}
ARTICLE
Hilsden RJ, Verhoef MJ, Best A, Pocobelli G. Complementary and alternative medicine use by Canadian patients with inflammatory bowel disease: Results from a national survey. Am J Gastroenterol 2003;98:1563-8.
\end{abstract}

\begin{abstract}
ARTICLE SUMMARY
Hilsden et al conducted a postal survey of members of the Crohn's and Colitis Foundation of Canada (CCFC), gathering data on the use of both conventional therapy and complementary and alternative medicine (CAM). The response rate was $76 \%$ (quite good for a mailed survey), although $9 \%$ of respondents stated that they did not actually have inflammatory bowel disease (IBD) (their data were excluded from the analysis). The data regarding CAM use were difficult to follow, as there was a blending of past and current reported use of CAM, as well as of CAM use specifically for IBD as opposed to for non-IBD reasons. Current or past use of CAM for IBD was reported by $47 \%$ of respondents, and ongoing use for IBD specifically was reported by $24 \%$. It appears that most of the CAM used by IBD patients was not for their IBD. An important finding was that approximately half of IBD patients use CAM either for their IBD or for other reasons. The main CAM used was acidophilus (19\%), followed by massage (18\%) and flax seed (13\%).
\end{abstract}

\section{COMMENTARY}

Two issues that repeatedly arise in studies of this type are the characteristics of the population under study and which interventions are considered CAM. While the authors suggest that studies conducted in specialty clinics are biased, in fact, there may be a greater bias in surveying members of an organization such as CCFC. Firstly, some members do not actually have IBD; while some survey respondents stated that they did not have IBD, others may have erroneously identified themselves as IBD patients. Furthermore, support groups such as CCFC might attract a distinct group of patients, or even patients who are more likely to use CAM since they have at least sought out a support group. CCFC members may be looking for something that their physicians cannot provide.

The second issue involves the definition of CAM. Special diets were used by $28 \%$ of respondents in this study, but should they be considered CAM? Nearly $8 \%$ used a gluten-free diet. Does the use of a gluten-free diet reflect a misinformed patient, a misinformed physician, or a patient actually with celiac disease? Other authors have included exercise and prayer (1) as forms of CAM, but Hilsden et al did not. Is exercise a CAM or is it something that should be advocated by all practitioners as health-promoting behavior (2)?

This study, like others before it $(1,3,4)$, have suggested that $30 \%$ to $60 \%$ of IBD patients use some form of CAM. At first glance, this may seem to be providing the following message to conventional doctors; "CAM use is rampant among IBD patients. Be open about it. Maybe even consider incorporating some of it." However, perhaps some of the results of this study soften the alarm bells and support the idea that conventional medical practice might be more acceptable than the proliferation of CAM studies suggests.

For instance, if $24 \%$ of IBD patients are using CAM specifically for their IBD, it begs the question as to whether or not the other $76 \%$ are quite satisfied with their conventional medical therapy. Alternatively, some of these patients might simply have not been informed about 'nonconventional' options.

In this study, a high proportion of past CAM users reported negative outcomes with CAM: either a worsening of at least one of their symptoms $(16 \%)$ or a perception that it had been a waste of money (33\%).

This study also supports the notion that practitioners are aware of the use of CAM. A total of 71\% of current CAM users had discussed their CAM use with their IBD doctor and only $13 \%$ believed that their doctor was not supportive of this practice.

Professor of Medicine, and Head, Section of Gastroenterology, Director, University of Manitoba Inflammatory Bowel Disease Clinical and Research Centre, Winnipeg, Manitoba, Canada

Correspondence: Dr Charles N Bernstein, John Buhler Research Centre, 804F-715 McDermot Avenue, Winnipeg, Manitoba

R3H 3P4. Telephone 204-789-3369, fax 204-789-3987, e-mail cbernst@cc.umanitoba.ca 
The authors postulated that patients choose CAM to exert control over their destinies. Can doctors not give patients increased control with conventional medication by abdicating a paternalistic approach to practice and by not only involving patients in choosing their therapies but also encouraging 'on demand' approaches to a variety of therapies (including oral 5-aminosalicylic acid dosing, initiation of rectal therapy, and possibly even the use of oral corticosteroids)? Perhaps there are inexpensive and safe CAMs, such as dietary manipulation, exercise or prayer, that can be endorsed by conventional medical practitioners, either because these modalities make sense for IBD patients or because they are accessible to most patients in some form or another and can enhance a patient's sense of control.

Finally, patients and primary care doctors frequently ask gastroenterologists about the efficacy and safety of many CAMs (particularly those that are ingested) in IBD. The Hilsden study and others like it remind the research community that, while novel biological agents are being studied in clinical trials, a large variety of widely available alternative interventions warrant assessment. In the absence of critical assessment, gastroenterologists could simply be supportive, cautious and open-minded. And with this positive interaction might come a therapeutic benefit as well (5).

\section{REFERENCES}

1. Rawsthorne P, Shanahan F, Cronin NC, et al. An international survey of the use and attitudes regarding alternative medicine by patients with inflammatory bowel disease. Am J Gastroenterol 1999;94:1298-303.

2. Loudon CP, Corroll V, Butcher J, Rawsthorne P, Bernstein CN. The effects of physical exercise on patients with Crohn's disease. Am J Gastroenterol 1999;94:697-703.

3. Hilsden RJ, Scott CM, Verhoef MJ. Complementary medicine use by patients with inflammatory bowel disease. Am J Gastroenterol 1998;93:697-701.

4. Moser G, Tillinger W, Sachs G, et al. Relationship between the use of unconventional therapies and disease-related concerns: A study of patients with inflammatory bowel disease. J Psychosom Res 1996;40:503-9.

5. Bernstein CN. The placebo effect for gastroenterology: Tool or torment. J Psychosom Res. (In press)

\section{The authors respond:}

Dr Bernstein provides an insightful commentary on our study of Canadian IBD patients' use of complementary and alternative medicine (CAM) (1). He describes the two main difficulties with studies of CAM: defining the study population and defining what is CAM. We agree that our sample may not be representative of the entire Canadian IBD population. However, it is a dramatically different and larger sample than those that have been studied before. For those who are interested, we have published a companion article from this study that discusses how our sample differs from our previous clinicbased sample and from a Canadian population-based sample (Dr Bernstein's University of Manitoba IBD Database) (2). For example, compared with a clinic-based sample, our sample included a broader range of patients, including patients with less severe disease and those with ulcerative colitis who had undergone surgery. Compared with the population-based sample, our sample was older and better educated, and included greater proportions of females and patients with Crohn's disease. When it is not possible to study a truly representative sample, sampling from different segments of that population can provide useful insights into the population as a whole. In our other paper, we also discuss why we believe that the risk of inclusion of non-IBD patients in the sample was small, because of the medical, surgical and medication history that respondents provided when completing the questionnaire.

Deciding what therapies to include as CAM can also be difficult. Some therapies, such as homeopathy and chiropractic, are clearly within the realm of CAM. But what about acidophilus, fish oil, pancreatic enzymes and various diets? Probiotics are the focus of intense research activity and could, in the future, become part of the standard treatment of IBD. But does that mean that any of the currently available products containing acidophilus or other purported beneficial bacteria will no longer fall under the rubric of CAM or that they should not be considered CAM today? In our research, we classify as CAM therapies those which patients have used that were not recommended by a medical doctor or other conventional health care provider, even if they would be regarded as conventional therapies in another situation. Therefore, a glutenfree diet would be considered conventional therapy for celiac disease but a CAM if used for IBD (in our questionnaire, we asked patients to include dietary therapies as CAM only if they were not recommended by a medical doctor or a dietician).

The inclusion of prayer and exercise is even more difficult. We asked patients about the use of prayer and exercise, but did not include them as CAM, as they are more commonly considered lifestyle behaviors. Exercise and prayer are not included in the NIH National Center for Complementary and Alternative Medicine's classification of CAM (3). We are currently writing a paper that examines patient factors associated with the use of CAM, including exercise and prayer, and also the reasons people gave for using or not using CAM. This paper will also provide some answers to the questions that Dr Bernstein poses about satisfaction with conventional therapy as a deterrent to CAM use and patients' desire for control.

Robert J Hilsden MD PhD FRCPC, Assistant Professor Departments of Medicine and Community Health Sciences, University of Calgary rhilsden@ucalgary.ca

Marja J Verhoef PhD, Professor Canada Research Chair in Complementary Medicine, Department of Community Health Sciences

\section{REFERENCES}

1. Hilsden RJ, Verhoef MJ, Best A, Pocobelli G. Complementary and alternative medicine use by Canadian patients with inflammatory bowel disease: Results from a national survey. Am J Gastroenterol 2003;98:1563-8.

2. Hilsden RJ, Verhoef MJ, Best A, Pocobelli G. A national survey on the patterns of treatment of inflammatory bowel disease in Canada. BMC Gastroenterology 2003;3:10.

3. What is complementary and alternative medicine?

$<$ http://nccam.nci.nih.gov/health/whatiscam/> (Version current at December 18, 2003). 


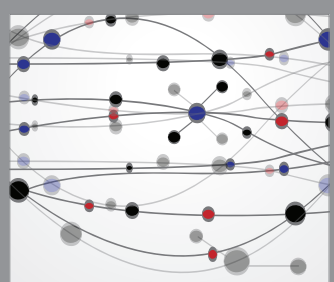

The Scientific World Journal
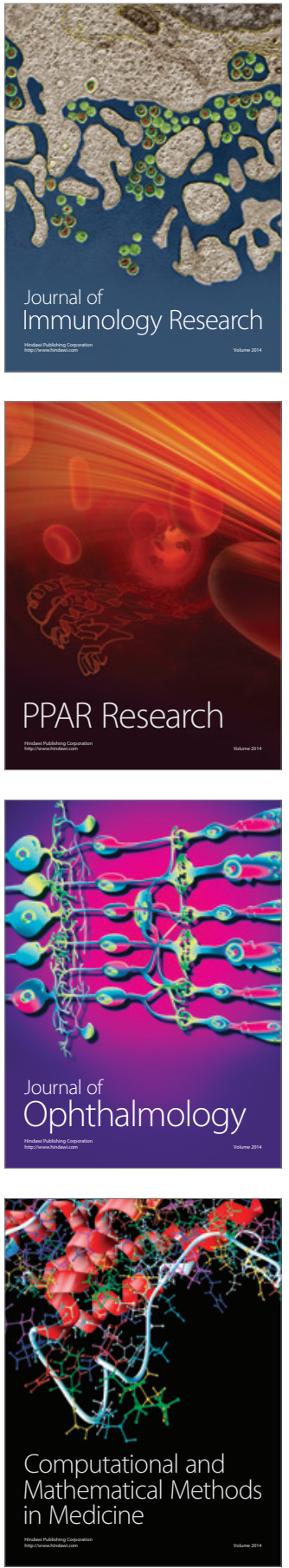

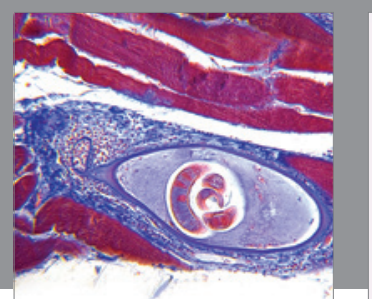

Gastroenterology Research and Practice

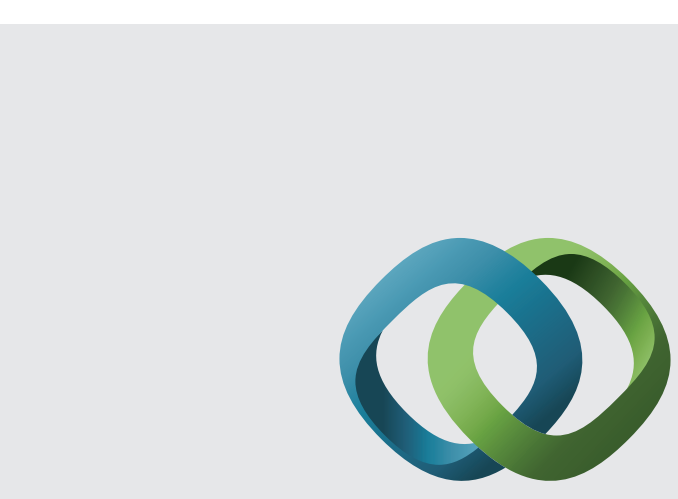

\section{Hindawi}

Submit your manuscripts at

http://www.hindawi.com
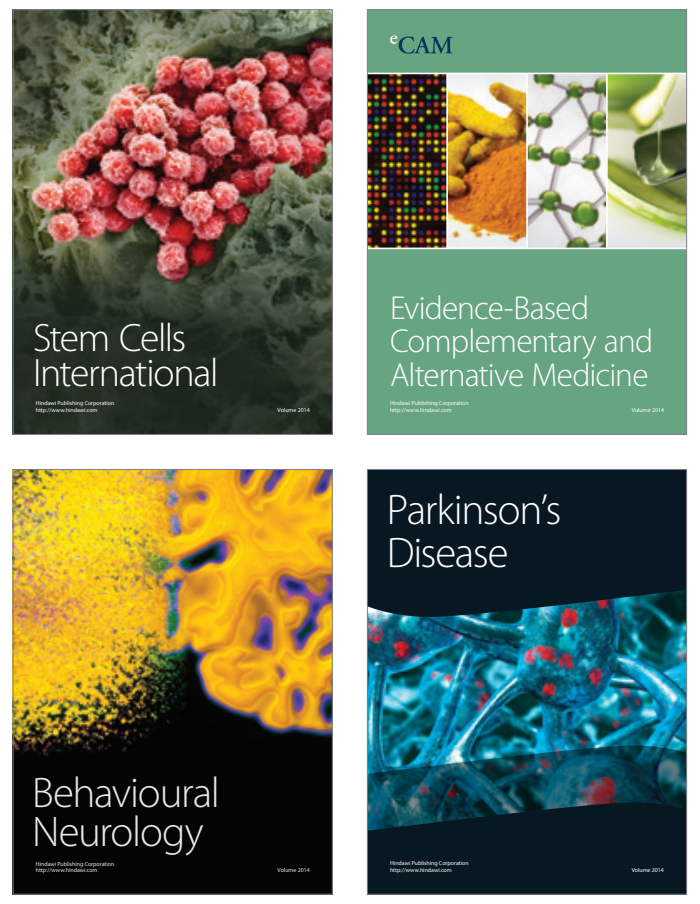
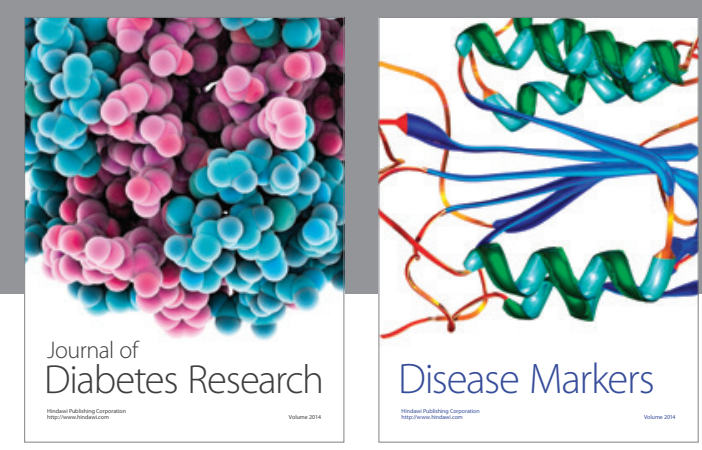

Disease Markers
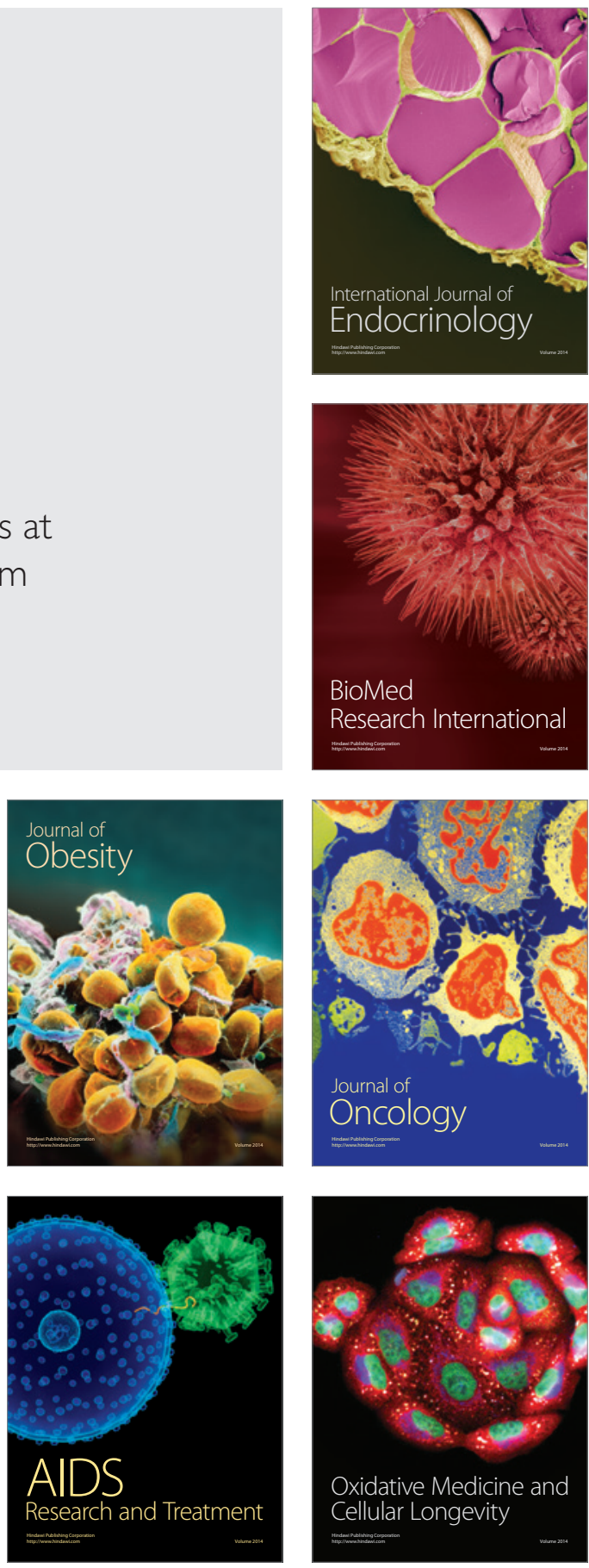